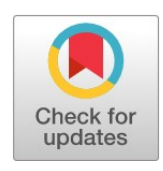

\title{
The effect of woman health nursing problem-based learning on self-efficacy, self-directed learning and problem-solving ability
}

\author{
Cha Mi-Youn * \\ Uiduk University, Gyeongju, South Korea
}

\author{
Keywords \\ Woman health nursing \\ Problem-based learning \\ Self-efficacy \\ Self-directed learning \\ Problem-solving ability \\ Received: 7 November 2020 \\ Accepted: 15 March 2021 \\ Published: 26 March 2021
}

\begin{abstract}
This study examined the effect of women health nursing problem-based learning programs for nursing students on self-efficacy, self-directed learning, and problem-solving ability. It is a quasi-experimental study for the pre/posttest design of a nonequivalent control group. An experimental group and a control group had 43 participants each for this study $(n=86)$. This test operated the Problem-Based Learning (PBL) program for the experimental group and gave a lecture instruction class to the control group. The two groups were surveyed to check the program's effect on self-efficacy, self-directed learning, and problem-solving ability at the same time by the pre/post-test. Thus, it was found out that the problem-solving ability was $p=.001$, and the self-efficacy was $p=.005$, which meant that the PBL program had significantly influenced. Therefore, it is implied that the PBL program can be helpful to the problem-solving ability and self-efficacy of women health nursing learning. The constant introduction of this program is regarded to be able to develop their creative quality.
\end{abstract}

(C) 2021 The Author(s). Published by TAF Publishing

\section{INTRODUCTION}

Education for nursing students to adjust rapidly changing medical environments is required to have a new learning method of exploring information on their own and building an ability to cope with in a creative direction (Bae, Lee, Kim, \& Sun, 2005; Meidrina, Mawaddah, Siahaan, \& Widyasari, 2017). College education needs efforts to enhance the quality of it. To deal with such social requirements, a variety of learning methods have been developed and operated. The higher students' efficacy is, the more learning ability they strength. Self-efficacy is an ability to come from belief and confidence for oneself, organizing their actions to produce outcomes (Bandura, 2006).

Bandura mentioned that self-efficacy is an essential ability among self-directed ones. This ability helps determine a faith to achieve some goals with efforts and constant responses (Bandura, 1986). In case that self-efficacy of students is high, they are more likely to do their per- sonal behaviors, have the power of control and take selfdirected actions without fear for mistakes (Malinauskas, 2017; Qalati, Ahmed, Mei, Thu, \& Sohu, 2020). Learners with high self-efficacy are task-oriented, prefer challenging tasks and perform higher problem solving and selfdirectedness than those with low belief of success and control (Eggen \& Kauchak, 1999). Self-directedness is an important ability to affect self-directed learning and problemsolving ability so it is an important task to improve learning ability of college students according to requirements of the future society (Eunmo, 2018).

Self-directed learning is to reinforce an effort that one intends to put for oneself as a part of active learning. The improvement of active study pursues independent study, organizes information, raises a capability to develop and extend their learning and has a keen interest and desire to find out and learn on their own (Koh, 2002). Self-directed learning that students make their own decisions and practice re-

* corresponding author: Cha Mi-Youn

†email: mycha@uu.ac.kr 
sponsibility to obtain outcomes is an important behavior in nursing education. In particular, population change in Korea due to low birth rate and growth of infertility women (Lee, Chulhee, 2012) demands more variant woman health nursing. Which asks nursing students to implement active study and advance problem-solving ability.

College operates diverse learning methods to strength student capabilities. As an enhanced education alternative in an intellectual society, problem-based learning is in progress. This study is a process, starting to find out problems first of all and exploring information, finally drawing up answers and estimating. Before the study, students should take into consideration what to learn (Cho \& Woo, 2003). Problem-based learning shows significant cognitive learning effects, such as accomplishment, problem-solving ability, critical insight, adaptability, acquisition, compared with lecture class effects, and especially, it works effectively in affective learning, such as learning interest, sociality, inner motivation (Hong, 2008).

Therefore, this study mainly aims to look into the effect of woman health nursing on self-efficacy, self-directed learning and problem-solving ability of a learning group which has a normal lecture class and learners who are educated by a problem-based learning method.

\section{Research Purpose}

The purpose of this study is to investigate the effect of woman health nursing PBL of nursing students on selfefficacy, self-directed learning and problem-solving ability.

\section{METHODOLOGY}

\section{Research Design}

A research design is aimed to figure out the effect of Woman Health Nursing PBL on self-efficacy, self-directed learning, and problem-solving ability. This study is a nonequivalent control group pre/post-test design as quasi-experimental research.

TABLE 1. Research design

\begin{tabular}{llll}
\hline \hline Group & Pre-Test & Treatment & Post-Test \\
\hline Cont. & Y1 & - & Y2 \\
Exp. & Y1 & $\mathrm{X}$ & Y2 \\
\hline \hline
\end{tabular}

Cont: Control group, Exp: Experimental group

Y1: General Characteristics, Self-efficacy, Self-directed learning, and Problem-solving Ability.

Y2: Self-efficacy, Self-directed Learning and Problemsolving Ability.

X: Woman Health Nursing PBL

\section{Data Analysis}

Data was confirmed by descriptive statistics which showed average and percentage of subjects' general characteristics by using SPSS 20 program and cross analysis (X2-test). Independent sample $t$-test was conducted to verify homogeneity between the two groups. The differences of pre/post self-efficacy, self-directed learning and problemsolving ability between the experimental and the control group were analyzed by paired $t$-test.

\section{Term Definition}

\section{PBL}

PBL is an education process of timely importance to improve problem solving ability and critical thinking of nursing students. It helps them seek their goals and solutions to handle their learning problem situations initially and creatively. They go through the process by experiencing unstructured problems of knowledge (Cho \& Woo, 2003). This study suggests health problems according to a female life cycle and means teaching and learning, including group discussion activities, presentation activities for solving problems.

\section{Self-efficacy}

The scale tool of self-efficacy which (Y. Lee \& Ji, 2017) developed consists of total 12 questions: 1 st factor-5 questions of negative efficacy, 2 nd factor - 5 questions of positive efficacy, 3rd factor-2 questions of social efficacy. It means that the higher a test grade is, the higher the self-efficacy is. The study showed that the 1st factor was Cronbach's $\alpha=.889$, the 2nd factor was Cronbach's $\alpha=822$ and the 3rd factor was Cronbach's $\alpha=.86$.

\section{Self-directed Learning}

The scale tool of self-directed learning, developed by (S.-J. Lee, Chang, Lee, \& Park, 2003) composes learning plan ability factors (learning desire diagnosis, goal setting, resource identification), learning practice ability factors (selfmanagement, learning strategy, continuity of learning practice) and learning evaluation factors (effort to attribute the result, self-examination). It is evaluated by 5 point scale, which means that the higher a test grade is, the higher the self-directed learning ability is. It has total 45 questions and the test reliability is Cronbach's $\alpha=.93$ and this study's reliability is Cronbach's $\alpha=.899$.

\section{Problem-solving ability}

It was developed to measure problem-solving ability of college students by Korea Educational Development Institute (A. N. Kim, Kim, Kim, \& Lee, 2003). It is a 5-point scale with 
a total of 45 questions. The higher a grade is, the better the problem-solving ability is. The inverse questions of this tool were 2-2, 2-3, 2-5 in a data collecting area of cause analysis and Cronbach's $\alpha=.94$ when the tool was developed and the reliability of this study, Cronbach's $\alpha=.880$.

\section{Subjects of Research}

The subjects of this study are the 4th grade nursing students from different colleges in a region through convenient sampling. They were assigned in experimental and control groups and agreed to join this study by written consent. Power Analysis was set by level of significance $(\alpha)=.05$, number of subjects $=2$, Power $=.90$, effect size $=.80$ and the two groups with 43 members each were suveyed (Cohen, 1988). The experimental group was processed through PBL team activities by 2 hours a day for 6 weeks and the control group was implemented by pre/post-tests at the same period.

\section{Application of Woman Health Nursing PBL}

The final goal of this study is to develop educational materials for health problems through PBL according to a female life cycle. It set up concepts and developed education tools for the PBL program by dividing the participants into 4 teams and letting them have discussion activities by 2 hours a day for total 6 weeks.

1. Concept setting of health problems

- Team 1: Health problems of infertile married couples

- Team 2: Health problems of menopausal women

- Team 3: Sex education problems of adolescents

- Team 4: Health problems for 100 days of postnatal care

2. Configuration of health concept map and situation choice
- Setting and stating a proposed problem learning goal

- Health concept setting according to suggested problems

- Writing a study plan

- Team rules and division of roles

- Team discussion and Information collection of health problems

- Health problem hypothesis setting through seminars

- Development of health improvement education tools

3. Presentation of developed tools

- Presentation of developed health promotion issues

- Team learning report

- Learning evaluation and reflection (Self-evaluation, team evaluation, instructor evaluation)

4. Evaluation tools to verify the effect

- Measurement of self-efficacy, self-directed learning and problem-solving ability

\section{RESEARCH CONSEQUENCES}

In gender comparison, the female students were surveyed more than about $70 \%$ in this study. Most of the control group were examined to be above average and $72 \%$ of the experimental group were examined to be above average in the major satisfaction level. Self-directed learning ability that the students perceive was identified that $86 \%$ of the experimental group and $76 \%$ of the control group were over average. The problem-solving ability level that they recognize was shown that $86 \%$ of the control group and $93 \%$ of the experimental group replied more than average. And, the most preferred learning type of the two groups was a lecture class and the least one was a debate class. The homogeneity based on the participants' characteristics had no significant difference (Table 2).

TABLE 2. Homogeneity test of general characteristics $(N=86)$

\begin{tabular}{|c|c|c|c|c|c|}
\hline \multicolumn{2}{|l|}{ "Characteristics } & \multirow{2}{*}{$\begin{array}{l}\text { Cont. }(n=43) \\
n(\%)\end{array}$} & \multirow{2}{*}{$\begin{array}{l}\text { Exp. }(n=43) \\
n(\%)\end{array}$} & \multirow[t]{2}{*}{$\overline{x^{2}}$} & \multirow[t]{2}{*}{$\bar{p}$} \\
\hline & & & & & \\
\hline \multirow[t]{2}{*}{ Gender } & Male & $13(30.2)$ & $6(14.0)$ & .608 & .649 \\
\hline & Female & $30(69.8)$ & $37(86.0)$ & & \\
\hline \multirow[t]{3}{*}{ Major Satisfaction level } & Satisfaction & $22(51.2)$ & $10(23.3)$ & .758 & .685 \\
\hline & & Average & $21(48.8)$ & $21(48.8)$ & \\
\hline & $\leq$ Average & $0(0.0)$ & $12(27.8)$ & & \\
\hline \multirow[t]{3}{*}{ Self-directed learning ability } & High & $3(7.0)$ & $5(11.6)$ & 1.520 & .823 \\
\hline & Average & $30(69.8)$ & $32(74.4)$ & & \\
\hline & Low & $10(23.3)$ & $6(14.0)$ & & \\
\hline \multirow[t]{3}{*}{ Own problem-solving skills } & High & $3(7.0)$ & $4(9.3)$ & 2.237 & .692 \\
\hline & Average & $34(79.0)$ & $36(83.7)$ & & \\
\hline & Low & $6(14.0)$ & $3(7.0)$ & & \\
\hline \multirow[t]{4}{*}{ Preferred learning Type } & Lecture & $16(37.2)$ & $28(65.4)$ & 1.316 & .325 \\
\hline & Debate & $3(7.0)$ & $1(2.3)$ & & \\
\hline & Video & $13(30.2)$ & $9(20.9)$ & & \\
\hline & Multiple & $11(25.6)$ & $5(11.6)$ & & \\
\hline
\end{tabular}




\section{Homogeneity Examination of Research Subjects}

The homogeneity of each pre-score between the groups was verified before examining the effect of self-efficacy, selfdirected learning and problem-solving ability of the subjects. Thus, independent sample $t$-test was implemented to get pre-test scores of each measurement tool. As a result, there was no significant difference in all the measured indexes from the experimental and control groups, which confirmed that they had the homogeneity (Table 3).

TABLE 3. Pre-test scores for the homogeneity

\begin{tabular}{llllll}
\hline \hline Variables & Groups & $\boldsymbol{M}$ & $\boldsymbol{S D}$ & $\boldsymbol{t}$ & Sig. \\
\hline Self-efficacy & Exp. $(n=43)$ & 3.299 & .287 & -1.753 & .321 \\
Cont. $(n=43)$ & 3.418 & .339 & & & \\
Self-directed Learning & Exp. $(n=43)$ & 3.409 & .310 & .381 & .09 \\
Cont. $(n=43)$ & 3.377 & .457 & & & \\
Problem-solving Ability & Exp. $(n=43)$ & 3.280 & .347 & -2.744 & .367 \\
Cont. $(n=43)$ & 3.507 & .414 & & & \\
\hline \hline
\end{tabular}

\section{Effect of PBL on Self-efficacy, Self-Directed Learning and Problem-Solving Ability}

To search group changes of self-efficacy, self-directed learning and problem-solving ability of the applicants, the corresponding sample $t$-test for pre/post variation was conducted. According to the result, it was proved that there were significant differences in self-efficacy and problem- solving ability. Self-efficacy had increased considerably from pre-score $(M=3.299)$ to post-score $(M=3.499)$. Problem solving ability level had increased from pre-score $(M$ $=3.280)$ to post-score $(M=3.632)$, too. However, selfdirected learning was surveyed to have no significant difference (Table 4).

TABLE 4. Effect of PBL on self-efficacy, self-directed learning ability and problem-solving ability

\begin{tabular}{|c|c|c|c|c|c|}
\hline Variables & Categories & Cont. $(n=43)$ & Exp. $(n=43)$ & $x^{2}$ & $\mathbf{p}$ \\
\hline & & $M(S D)$ & $M(S D)$ & & \\
\hline \multirow[t]{2}{*}{ Self-efficacy } & Pre & $3.418(.339)$ & $3.299(.287)$ & $-2.941^{*}$ & .005 \\
\hline & Post & $3.405(.322)$ & $3.499(.327)$ & & \\
\hline \multirow[t]{2}{*}{ Self-directed Learning } & Pre & $3.377(.457)$ & $3.409(.310)$ & -.471 & .640 \\
\hline & Post & $3.357(.451)$ & $3.443(.433)$ & & \\
\hline \multirow{2}{*}{$\begin{array}{l}\text { Problem-solving } \\
\text { ity }\end{array}$} & Pre & $3.507(.414)$ & $3.280(.347)$ & $-3.576^{*}$ & .001 \\
\hline & Post & $3.493(.345)$ & $3.632(.511)$ & & \\
\hline
\end{tabular}

$* p<.05$

\section{DISCUSSION}

This study applied the woman health nursing problembased learning program to nursing students. It was carried out to understand the influence on their self-efficacy, self-directed learning and problem-solving ability. The 4th grade nursing students in a region were surveyed by the forms of pre-test, program execution and post-test.

The result was that the effect of woman health nursing PBL program intervention on the applicants' self-efficacy had no significant difference in the control group. However, there was a significant difference in the experimental group. It was examined to increase from the pre-score 3.299(.287) to the post-score $3.499(.327)$. Self-efficacy is a concept to express one's concrete confidence for a certain result. It is classified into general efficacy and social efficacy. General efficacy is a belief in oneself that one can achieve under normal circumstances. Social efficacy is an capability to make new positive colleague relation and a faith to respond amicably to the surroundings (Y. Lee \& Ji, 2017). Studies on influence of efficacy have been widely released. People with low efficacy are more likely to avoid difficult environments or tasks. They are mostly less passionate and weak at executing goal achievement. Moreover, they tend to have lack of performance by quitting quickly, which can be a stressor. On the contrary, people with high confidence establish their goals for tasks by themselves and fulfill suc- 
cessfully with challenge and internal focus (Bandura, 2004). The best thing to advance efficacy is to make use of problemsolving methods multiple times for personal success experience. In this way, efficacy became higher through the efforts of changing surrounding acquaintances and circumstances in order to correct or remove the source of stress behaviorstrategically (M. A. Kim, 2002). Bandura (1986) study also mentioned that achievement was the most influential factor. I. Lee, Park, and Park (2015) reported that self-efficacy increased considerably like this study during PBL application to the students. If a person experiences to achieve continuous success, their efficacy rises high and a negative impact from failure reduces. Thus, it will help improve their efficacy to provide various programs for problem settlement. It was identified that self-directed learning ability of the applicants based on woman health nursing PBL had no significant differences in both experimental and control groups. Self-directed learning is to study independently by constant self-monitoring the process of learning plan, practice, assessment and correction with responsibility. Basic assumption is that students have their own ability to learn, which means active self-control learning based on cognitive, linguistic, motivational, environmental judgment standards. Motivation of self-directed learning depends on the formation and management of education courses which respect each individuality (Joo, 2003).

The system of an organization may not be operated well by manuals only. It can be supplemented by consultation with others and personal active experience. And, self-directed learning is a very important factor to develop autonomy, independence and emphasized expertise in unofficial learning, too (Yoo \& Lee, 2020). In this study, there was no considerable increase but in the study of I. Lee et al. (2015) there appeared to increase quite noticeably. By applying PBL, learners get to have confidence and interest in education. And, a team activity can be a chance to experience the effect of collaborative learning with teammates (H. J. Kim, 2020).

The effect of woman health nursing PBL research on the applicants' problem-solving ability had no significant difference in the control group. However, the pre-score of the experimental group had been changed from 3.280(.347) to 3.632(.511) considerably. While learners set and achieve their learning goals through voluntary and active education, they develop confidence, interest and divergent thinking ability. Thus, they get to immerse themselves in improved capability and interest in learning. When facing a given problem, they affect school classes positively with creative ideas (H. J. Kim, 2020). The studies of S. G. Lee and Kim
(2020) and S. Lee and Kim (2018) also showed the same outcome. Especially, great progress appeared in the whole average of learners and discovery and statement of problem, provision of ideas factors as subordinate scope. In this way, it gave a positive effect on attitude for curriculum (Song \& Hong, 2016). Collaborative learning is very important to enhance problem solving ability. Members work together to solve common problems for common goals, such as concession to teammates, forgiveness, waiting, suggestion, negotiation and being fair (Y. Lee \& Ji, 2017).

\section{CONCLUSION}

This is a quasi-experimental research using nonequivalent control/experimental groups and pre/post design to grasp the influence of woman health nursing PBL on self-efficacy, self-directed learning and problem-solving ability of nursing students. The 4 th grade nursing students in P city who agreed to understand the purpose of the research and attend it chose experimental and control groups by college randomly. The questionnaires were surveyed by the pretest and post-test. The result was summarized as follows: First, the general characteristics were that the female students outnumbered the male. The Major satisfaction was shown to be above average in the experimental and control groups. There were few students who thought to do high self-directed learning. And, there were few students who thought to have high problem-solving ability. The most preferred learning method was a lecture class and the next one was a video class.

Second, there was no significant difference in the two groups after the homogeneity test of the participants.

Third, it was investigated that the experimental group which took the PBL intervention had the higher level of selfefficacy than the control group which did not. There was no difference in the level of self-directed learning. In regard to problem solving ability, the experimental group was examined to have more significant difference than the control group in the statistics.

On the basis of these conclusions, woman health nursing PBL for the students has been revealed to elevate their selfefficacy and problem-solving ability. Constant introduction of this program is regarded to become education to develop their creative quality.

\section{LIMITATIONS AND RECOMMENDATIONS}

Since the conclusions were limited to the students of the region, it has difficulty generalizing it. Therefore, it is suggested to perform the research repeatedly in different regions or colleges. This study implies that PBL is effective in 
elevating self-efficacy of nursing students and had a statistically significant difference in problem solving ability. Based on the findings, introduction and constant application of
PBL should be examined and progressed to raise learning ability of the students.

\section{REFERENCES}

Bae, Y.-S., Lee, S.-H., Kim, M.-H., \& Sun, K.-S. (2005). Effects of pbl (problem-based learning) on self-directed learning and critical thinking disposition of nursing students. The Journal of Korean Academic Society of Nursing Education, 11(2), 184-190.

Bandura, A. (1986). Social foundations of thought and action. Englewood Cliffs, NJ: Sage Publications.

Bandura, A. (2004). Self- efficacy in changing socoetoes. Seoul, South Korea: Hakjisa.

Bandura, A. (2006). Guide for constructing self-efficacy scales. In F. Pajares and T. Urdan (Eds.), Self-efficacy beliefs of adolescents. New York, NY: H. H. Freeman.

Cho, Y., \& Woo, J. (2003). The view of knowledge and educational values in the problem-based learning. Korean Journal of Educational Research, 41(3), 571-600.

Cohen, J. (1988). Statistical power analysis for the behavioural sciences. Hillsdale, NJ: Laurence Erlbaum Associates.

Eggen, P. D., \& Kauchak, D. (1999). Educational psychology. Upper Saddle River, NJ: Prentice hall.

Eunmo, S. (2018). The influence of smart media literacy and learning agility on self-directed learning ability and problemsolving ability according to gender of university students in higher education. The Journal of Educational Information and Media, 24(4), 709-732. doi:https://doi.org/10.15833/KAFEIAM.24.4.709

Hong, K. (2008). A meta-analysis on the effects of problem-based learning. The Journal of Educational Information and Media, 14(3), 225-251.

Joo, H. S. (2003). Conceptualization of self-regulated learning and educational implications. The Journal of Curriculum Studies, 21(1), 203-221.

Kim, A. N., Kim, N. H., Kim, T. J., \& Lee, S. J. (2003). A study on the establishment of national lifelong learning standards and quality management system (II) (Technical report). Korea Educational Development Institute, Seoul, South Korea.

Kim, H. J. (2020). PBL application and effectiveness study in colleges: Music listening classes. Research in Music Pedagogy, 21(1), 23-42.

Kim, M. A. (2002). A study on the effect of coping methods of secondary trauma stress on self-efficacy of counselors of child abuse prevention center (Unpublished master's thesis). Ewha Womans University, Seoul, Korea.

Koh, L. C. (2002). The perceptions of nursing students of practice-based teaching. Nurse Education in Practice, 2(1), 35-43. doi:https://doi.org/10.1054/nepr.2002.0041

Lee, I., Park, H., \& Park, C. (2015). Effects of self-esteem, achievement motivation, self-efficacy \& self-directed learning on applying problem based learning in nursing students. Korean Journal of Military Nursing Research, 33, 134-144. doi:https://doi.org/I10.31148/kjmnr.2015.33.1.134

Lee, S., \& Kim, Y. (2018). The effects of pbl class on university student's creative problem solving competence, self-efficacy and class participation. Journal of Educational Innovation Research, 28(2), 73-89.

Lee, S. G., \& Kim, K. H. (2020). The effects of academic achievement on creative problem-solving competence and self-efficacy in PBL. Humanities and Social Sciences, 11(5), 247-257. doi:http://dx.doi.org/10.22143/HSS21.11.5.18

Lee, S.-J., Chang, Y.-K., Lee, H.-N., \& Park, K.-Y. (2003). A study on the development of life-skills: Communication, problem solving, and self-directed learning (Technical report). Korean Educational Development Institute, Seoul, South Korea.

Lee, Y., \& Ji, E. (2017). Development of self-efficacy scale. Korean Journal of Social Science, 36(1), 5-31.

Lee, Chulhee. (2012). A decomposition of decline in total fertility rate in Korea: Effects of changes in marriage and marital fertility. Korea Journal of Population Studies, 35(3), 117-144. doi:https://doi.org/G704-000152.2012.35.3.002

Malinauskas, R. K. (2017). Enhancing of self-efficacy in teacher education students. European Journal of Contemporary Education, 6(4), 732-738. doi:https://doi.org/10.13187/ejced.2017.4.732

Meidrina, T., Mawaddah, S. N., Siahaan, F. M. M., \& Widyasari, P. (2017). The relationship between teacher efficacy and attitude towards inclusive education in private elementary school: A study based on teaching experiences. Journal of Advances in Humanities and Social Sciences, 3(3), 124-134. doi:https://doi.org/10.20474/jahss-3.3.1 
Qalati, S. A., Ahmed, N., Mei, J., Thu, T. T. H., \& Sohu, J. M. (2020). Stay home stay safe: General public knowledge, attitude and behavior regarding COVID-19 during the lockdown in developing countries. International Journal of Humanities, Arts and Social Sciences, 6(2), 69-77. doi:https://doi.org/10.20469/ijhss.6.20002-2

Song, H. H., \& Hong, S. Y. (2016). Influence on problem-solving ability and attitude caused by applying PBL model to students with disabilities in ICT utilizing course. The Journal of Special Children Education, 18(1), 1-26. doi:http://dx.doi.org/ 10.21075/kacsn.2016.18.1

Yoo, M. J., \& Lee, D. M. (2020). Effect of self-directed learning and family support on professionalism in flight attendants. Journal of Human Resource Management Reaearch, 27(1), 61-83. doi:http://dx.doi.org/10.14396/jhrmr.2020.27.1.61 